\title{
Properties of Alkali-Resistant Glass Fiber Reinforced Coral Aggregate Concrete
}

\author{
Shutong Yang ${ }^{1,2}$, Miao Yu ${ }^{1}$, Kun Dong ${ }^{1, * \mathbb{C}}$ and Yushan Yang ${ }^{3}$ \\ 1 Department of Civil Engineering in College of Engineering, Ocean University of China, \\ Qingdao 266100, China; yangshutong@ouc.edu.cn (S.Y.); yumiao1179@stu.ouc.edu.cn (M.Y.) \\ 2 Cooperative Innovation Center of Engineering Construction and Safety in Shandong Blue Economic Zone, \\ Qingdao University of Technology, Qingdao 266033, China \\ 3 Department of Mathematics and Applied Mathematics, China University of Mining \& Technology, \\ Beijing 100083, China; 1710730132@student.cumtb.edu.cn \\ * Correspondence: dongkun@ouc.edu.cn; Tel.: +86-0532-66781548
}

Received: 10 July 2020; Accepted: 31 July 2020; Published: 5 August 2020

\begin{abstract}
The intention of this paper is to analyze the properties of coral aggregate concrete (CAC) that is reinforced by alkali-resistant glass fibers (ARGF) and the bond performance with BFRP (basalt fiber reinforced polymer) bars. Two types of ARGF, denoted by Type A and Type B with different manufacturing technologies and fiber lengths, are used in the test. Tests of compressive strength, splitting tensile strength, and flexural performance were performed on ARGF-CAC with four different contents for the two types of ARGF. It is found that the cubic compressive strength is slightly reduced when the fiber volume fraction exceeds $0.5 \%$, but almost keeps invariable if the fiber content further increases. However, the tensile strength, residual strength retention and flexural toughness are improved as more ARGFs are added into CAC, and even higher with Type B ARGF addition. The optimized volume fraction is $1.5 \%$ for both the two types of ARGF based on the evaluation of the workability and mechanical performance. Moreover, central pull-out test was performed to study the bond properties of ARGF-CAC with BFRP bars. It is found that both the maximum average bond stress and residual frictional stress are generally reduced as the bond length is longer. The addition of Type B ARGFs can significantly improve the bond strength; however, the Type A ARGFs seem to have marginal effect.
\end{abstract}

Keywords: coral aggregate concrete (CAC); alkali-resistant glass fiber (ARGF); flexural performance; BFRP bar; bond properties

\section{Introduction}

Concrete, as a commonly used construction material, can be widely used in civil engineering. Portland cement, river sands, and crushed stones are essential components in conventional concrete. However, a large amount of $\mathrm{CO}_{2}$ emission is inevitable during the cement production [1]. Natural aggregates become scarcer due to the exhaustive exploitation. Researchers attempt to develop replacements of the mentioned ingredients in concrete for the sustainable development of human society. Some minerals having aluminosilicates, such as ground granulated blast furnace slag, fly ash, metakaolin, et al., can be adopted in order to produce alkali-activated materials (AAMs) by using alkali-activators [2]. The Portland cement can be then completely replaced by AAMs in order to mix concrete [3,4]. Besides, some glass waste [5], construction and demolition waste [4,6] can be recycled as fine and coarse aggregates instead of natural aggregates. Eco-friendly green concrete is consequently obtained [4,5]. Moreover, it is well known that the ocean area is much larger than the mainland area on the earth. The latter becomes limited with the rapid development of human society. A great 
number of marine engineering constructions will be an inevitable trend in the near future and a large amount of concrete would be then utilized. If all the raw materials for concrete mixing are transported by ships from the mainland, the construction cost will be increased and the period becomes longer. Therefore, it is necessary to adopt seawater and sea aggregates instead of the conventional ones in mixing concrete. If so, most of the raw materials can be locally obtained, and the construction cost and period are consequently reduced.

In some islands near tropics, such as South China Sea, there are abundant coral reefs. They can be utilized in a rational manner if no damage is ensured in local ecologies. Subsequently, it is feasible to use the crushed coral reefs as aggregates in concrete production [7]. As the products of many dead coral insects after thousands of years, the main mineral components of coral aggregates are calcium carbonate [8,9], which show considerable difference from those of natural aggregates. The surfaces of coral aggregates are porous and then the aggregates must have high water absorption. Therefore, the coral aggregates are generally pre-soaked in the water before they are mixed in concrete [9]. Because of the high water absorption and irregular shapes of coral aggregates [10], the workability of fresh coral aggregate concrete (CAC) is reduced. However, the early strength develops faster than that of ordinary concrete due to the chloride effects transferred from seawater and coral aggregates [11-14]. The seven-day strength even exceeds $80 \%$ of the 28 -day strength $[13,14]$. Besides, the coral aggregates generally have sufficient bond performance with the surrounding paste and the interfacial transition zones are hardly detected $[15,16]$. Thus, the fracture of coral aggregates is a common failure mode in CAC [17]. Lyu et al. [18] analyzed the effects of sphericity, angular number and index, shape, and texture of coral particles on the properties of CAC. Incorporations of fly ash, blast furnace slag and metakaolin into CAC can improve the durability of the resulting concrete [19]. As the curing age increases, some of the water in the pre-soaked aggregates would be released and further hydration reaction occurs, which results in subsequent strength improvement [20]. Moreover, because both the seawater and coral aggregates may have high saline content, steel bar cannot be effectively used in reinforced CAC structures. Fiber-reinforced polymer (FRP), as a non-metallic material, can be used instead of steel in CAC structures [13,17,21,22], due to its high resistance to chloride corrosion. Yang et al. [13] analyzed the bond behavior between CAC and FRP bars with different FRP types, diameters, surface types, bond lengths, and curing conditions. Basalt FRP (BFRP) bars have good durability in CAC that is immersed in saline solution [17]. However, Wang et al. [21] found that the bond strength is reduced under the condition of seawater immersion with high temperature. FRP tube can be used as confinement in CAC columns under compression to prevent the spalling failure of CAC [22].

Furthermore, it is found that the failure characteristics of CAC are more brittle than those of ordinary concrete [22-25]. The ratio of compressive strength to tensile strength is larger and the fracture toughness and energy are lower when compared to ordinary concrete [20]. Therefore, it is necessary to add fibers into concrete to improve both the tensile resistance and toughness [23]. Researchers have attempted to introduce carbon fibers [26], polypropylene fibers [26], sisal fibers [26], and basalt fibers $[27,28]$ into CAC. As the plastic waste is efficiently recycled, Małek et al. [29] successfully added recycled polypropylene plastic fibers in concrete and Kim et al. [30] introduced recycled PET (polyethylene terephthalate) fibers. The results show that the compressive strength, splitting tensile strength, and modulus of rupture are increased with the fiber content, which varies in a certain range [26-29], and the permeability and shrinkage are reduced [30]. Moreover, glass fibers have been used in civil engineering since the late 1960's [31]. However, if they are directly added into concrete, the fibers would be corroded under the high alkaline environment. When the surfaces of the fibers are coated with Zirconia having the weight fraction of $15 \%$ or more, the alkali-resistance can be improved [31]. Thus, alkali-resistant glass fibers (ARGF) are produced and widely used in construction materials. Incorporating ARGFs can significantly increase the splitting tensile strength [32-37], modulus of rupture [32-37], flexural toughness [32], and wearing resistance of concrete [33] if no agglomeration of fibers occurs. Crack initiations and propagations are much suppressed, and the maximum crack width 
and length are reduced [32,35,38]. Proper surface sizing can enhance the environmental resistance of ARGF [31,39]. Besides, the degradation of ARGF in concrete in the aggressive environment is weakened if fly ash and silica fume are incorporated in the concrete [33,40,41]. The resistance to permeability of ARGF reinforced concrete is improved [42].

Although the ARGF is widely used in ordinary concrete, studies on ARGF reinforced CAC are relatively few to our best knowledge. Lu et al. [43] analyzed the cubic strength, splitting tensile strength and resistance to chloride permeability of ARGF-CAC. Only one type of ARGF is considered. In fact, the flexural performance, especially the flexural toughness, should be studied after the addition of ARGFs. Besides, once the ARGF-CAC is used in structures, the bond performance between FRP bars and ARGF-CAC is important and it would dominate the structural behaviors. Thus, the intention of this paper is to study the mechanical properties of ARGF-CAC with different ARGF types and relatively large variation ranges of fiber contents. The bond performance between Basalt FRP (BFRP) bars and ARGF-CAC is then investigated by considering different ARGF types, fiber contents, and bond lengths.

\section{Experimental Programme}

\subsection{Raw Materials}

In the present study, ARGF reinforced CAC (ARGF-CAC) is mixed by seawater, cement, ground granulated blast furnace slag (GGBFS), Class F fly ash (FA), metakaolin (MK), coral aggregates, and ARGF according to the literature [19]. All of the water used in the test is artificial seawater simulating the water in South China Sea [13]. Ordinary Portland cement (P.O. 42.5) is used as the cement and it is partially replaced by the GGBFS, FA, SF, and MK as the cementing materials. Table 1 provides the main mineral compositions of the latter three admixtures using a X-ray fluorescence (XRF) spectrometer, as per BS EN1926-2 [44]. Figure 1 displays the coral aggregates used in the test. The apparent and bulk densities are $2517 \mathrm{~kg} / \mathrm{m}^{3}$ and $1236 \mathrm{~kg} / \mathrm{m}^{3}$ for coral sands, and $1899 \mathrm{~kg} / \mathrm{m}^{3}$ and $918 \mathrm{~kg} / \mathrm{m}^{3}$ for coral coarse aggregates (CCA). Coral sands have a continuous gradation of $0-5 \mathrm{~mm}$ and coral coarse aggregates have two continuous gradations of 5-10 $\mathrm{mm}$ and 10-20 $\mathrm{mm}$, respectively. Figure 2 shows the size distributions.

Table 1. Mineral compositions of admixtures (\%).

\begin{tabular}{cccccccccc}
\hline Type & $\mathbf{C a O}$ & $\mathrm{SiO}_{\mathbf{2}}$ & $\mathrm{Al}_{\mathbf{2}} \mathbf{O}_{3}$ & $\mathbf{M g O}$ & $\mathrm{SO}_{3}$ & $\mathrm{TiO}_{2}$ & $\mathrm{Fe}_{\mathbf{2}} \mathbf{O}_{3}$ & $\mathbf{K}_{\mathbf{2}} \mathbf{O}$ & $\mathrm{Na}_{2} \mathbf{O}$ \\
\hline FA & 8.4 & 41.7 & 34.2 & 1.15 & 1.51 & 1.63 & 5.92 & 0.89 & 3.26 \\
GGBFS & 38.3 & 30.3 & 16.04 & 8.26 & 2.75 & 2.22 & 0.63 & 0.449 & 0.406 \\
MK & 0.12 & 54.7 & 40.2 & 0.084 & 0 & 0 & 0.84 & 0 & 0 \\
\hline
\end{tabular}

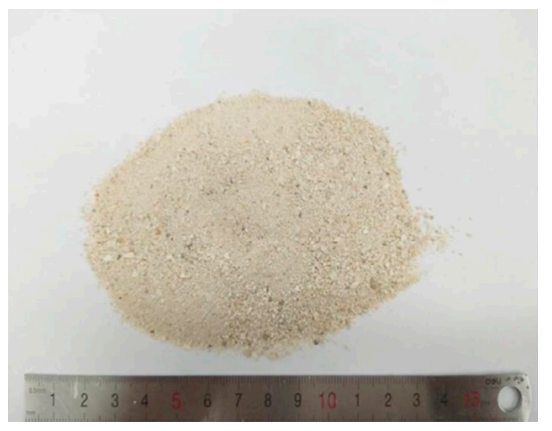

(a)

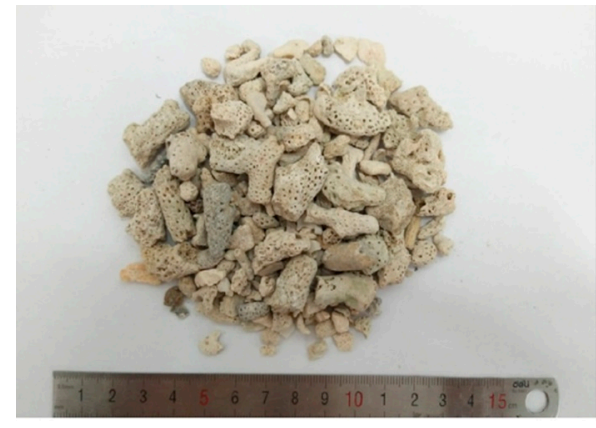

(b)

Figure 1. Coral aggregates used in the test: (a) Coral sand; and, (b) Coral coarse aggregate. 


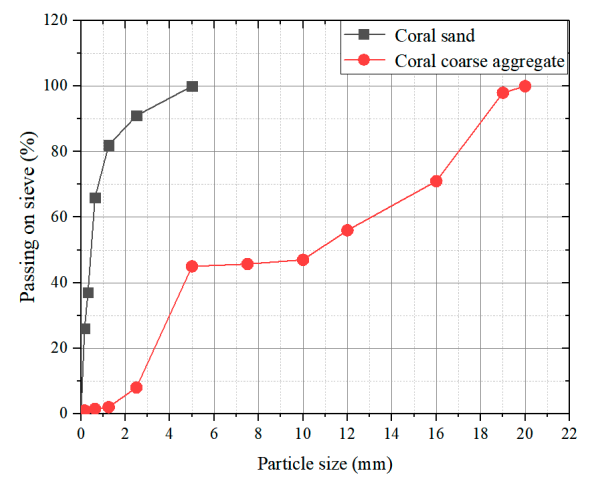

Figure 2. Size distributions of coral aggregates.

Two types of ARGF are used in the study and obtained from Tanshan Glass Fiber Limited Company. One of them is Cem-FIL 62 ARGF (denoted by Type A ARGF hereafter) with the length of $18 \mathrm{~mm}$ and elastic modulus of $72 \mathrm{GPa}$. It is bound by 200 fiber filaments with diameters $14 \mu \mathrm{m}$. The other one is HP-36 ARGF (denoted by Type B ARGF hereafter), which is bound by 600 fiber filaments with diameters $19 \mu \mathrm{m}$. It has the length $36 \mathrm{~mm}$ and elastic modulus $72 \mathrm{GPa}$. The densities of all the ARGFs are $2680 \mathrm{~kg} / \mathrm{m}^{3}$. The two types of ARGF are seen in Figure 3, as follows. Besides, all of the ARGFs are produced into thin slices and the detailed sizes of the slices are shown in Table 2. Polycarboxylate superplasticizer (PS) with water reducing rate $28 \%$ is used in order to improve the workability of fresh concrete.

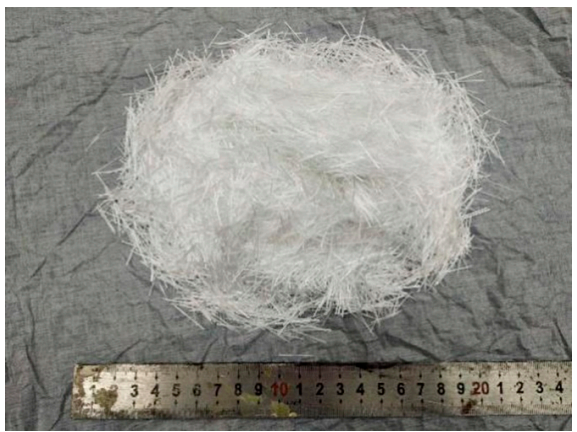

(a)

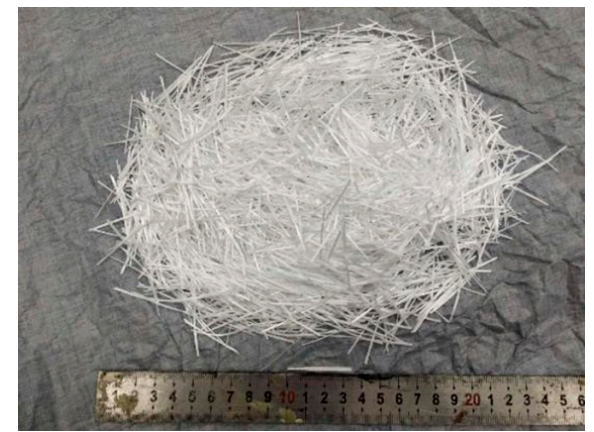

(b)

Figure 3. Alkali-resistant glass fibers (ARGF) used in the test: (a) Type A ARGF; and (b) Type B ARGF.

Table 2. Sizes of ARGF slices.

\begin{tabular}{cccc}
\hline Type of ARGF & Average Thickness (mm) & Average Width (mm) & Length (mm) \\
\hline Type A & 0.12 & 0.54 & 18 \\
Type B & 0.22 & 1.08 & 36 \\
\hline
\end{tabular}

BFRP bars are adopted to study the bond performance with ARGF-CAC. All of the bars have nominal diameters $8 \mathrm{~mm}$ and shallow ribs on the surface. It should be noted that the ribs are formed by detaching a demoulding belt, which is initially wound on the smooth surface of each bar. The detailed sizes of rib width and spacing for BFRP bar are shown in Figure 4, as follows. 


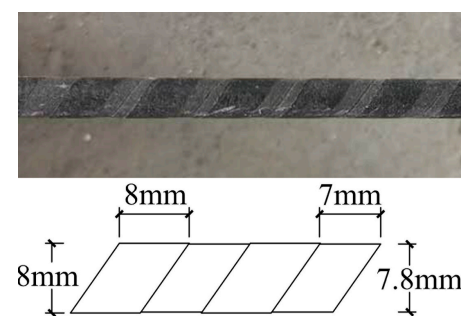

Figure 4. Basalt Fiber-Reinforced Polymer (BFRP) bar used in the study.

\subsection{Mix Proportion}

It should be noted that the two types of ARGF that are provided by Taishan Fiberglass Inc. have good dispersion properties in the paste. Therefore, relatively large variation ranges of fiber contents are considered in the present study. For each type of ARGF, four different fiber contents, i.e., $0.5 \%, 1 \%$, $1.5 \%$, and $2 \%$, in the form of volume fractions, are designed. The CAC with no fiber reinforcement is adopted as the control concrete. Moreover, Małek et al. [29] pointed out that the workability of fresh concrete becomes weaker as the fiber content increases. Because the fiber content varies in a relatively wide range in the present study, different superplasticizer additions are needed in order to ensure the slump of all the fresh concrete almost invariable. Thus, the ratios of the superplasticizer to the cementing materials are $0.55 \%, 0.85 \%, 1.05 \%, 1.25 \%$, and $1.55 \%$ for fiber volume fractions $0,0.5 \%, 1.0 \%$, $1.5 \%$, and $2.0 \%$, respectively. Therefore, five mix proportions of CAC are given in Table 3 , as follows, for either Type A or B ARGF.

Table 3. Mix proportion $\left(\mathrm{kg} / \mathrm{m}^{3}\right)$.

\begin{tabular}{|c|c|c|c|c|c|c|c|c|c|}
\hline Mix Symbol & Seawater & Cement & FA & GGBFS & MK & CS & CCA & PS & ARGF \\
\hline Base mix & & & & & & & & 2.75 & 0 \\
\hline Type A ARGF-0.5 & & & & & & & & 4.25 & 13.4 \\
\hline Type A ARGF-1.0 & & & & & & & & 5.25 & 26.8 \\
\hline Type A ARGF-1.5 & & & & & & & & 6.25 & 40.2 \\
\hline Type A ARGF-2.0 & 190 & 300 & 75 & 75 & 50 & 556 & 712 & 7.75 & 53.6 \\
\hline Type B ARGF-0.5 & & & & & & & & 4.25 & 13.4 \\
\hline Type B ARGF-1.0 & & & & & & & & 5.25 & 26.8 \\
\hline Type B ARGF-1.5 & & & & & & & & 6.25 & 40.2 \\
\hline Type B ARGF-2.0 & & & & & & & & 7.75 & 53.6 \\
\hline
\end{tabular}

\subsection{Mix Production}

All of the CCAs were pre-immersed in seawater for $23 \mathrm{~h}$ and left in dry condition for $1 \mathrm{~h}$ before they were prepared in mixing concrete. SJD-30 mix machine with the maximum range $33 \mathrm{~L}$ was used in order to mix the concrete. The rotation rate of the mixer is $45 \mathrm{r} / \mathrm{min}$. During the mixing process, all of the pre-immersed CCAs, coral sands, and cementing materials were first mixed for $30 \mathrm{~s}$ in the machine. The seawater and PS were then poured into the solid components. Moreover, the glass fibers are gradually added after the mixture was mixed for $120 \mathrm{~s}$. The fresh concrete is stirred sufficiently with the fiber addition, so that the fibers can be uniformly dispersed in concrete. The whole mixing time lasts about $6 \mathrm{~min}$. The mixing process in the present study is similar to that by Małek et al. [29]. When the fiber volume fraction attains $2 \%$, it is found that some difficulty is encountered more or less during the mixing process. A few fibers are even found to accumulate together. If the fiber content is increased further, the workability of fresh concrete may be too weak to be stirred, and even more PS is added. Segregation, bleeding, and agglomeration of fibers would be then inevitable. Therefore, the maximum fiber volume fraction is allowed to be $2 \%$ for both the two types of ARGF.

All of the mix was poured into the moulds for the test specimens, as mentioned in Section 2.5, Section 2.5, Section 2.5, Section 2.5, and compacted for $30 \mathrm{~s}$ at a vibration table. The samples were 
demoulded after $24 \mathrm{~h}$ and then cured in a room with temperature $20 \pm 2{ }^{\circ} \mathrm{C}$ and relative humidity $95 \%$. The tests began after 28 days of curing.

\subsection{Test on Slump of Fresh Concrete}

The slump values of fresh concrete were determined using a slump cone with the top and base diameters $100 \mathrm{~mm}$ and $200 \mathrm{~mm}$, respectively, and height $300 \mathrm{~mm}$, as per BS EN 12350-2 [45].

\subsection{Determination of Pore Solution $\mathrm{pH}$ Value}

The dust samples were extracted from the inner regions of the hardened concrete (about $30 \mathrm{~mm}$ from the exposed surface), and then dissolved in distilled water, as per RILEM TC 178-TMC recommendations [46]. The $\mathrm{pH}$ value is determined while using a $\mathrm{pH}$ meter.

\subsection{Test of Cubic Compressive Strength and Splitting Tensile Strength}

According to Chinese standard GB/T 50081 [47], three cubic specimens with sizes of $150 \times 150 \times 150 \mathrm{~mm}^{3}$ are adopted in order to determine the cubic compressive strength $f_{\mathrm{cu}}$ and three cubic specimens with sizes of $150 \times 150 \times 150 \mathrm{~mm}^{3}$ are used to determine splitting tensile strength $f_{\mathrm{ts}}$. Figure 5 shows the details of cubic compressive strength test with the loading rate $0.6 \pm 0.2 \mathrm{MPa} / \mathrm{s}$, as recommended by BS EN 12390-3 [48]. The $f_{\text {cu }}$ can be expressed by

$$
f_{c u}=\frac{F_{u}}{A}
$$

where $F_{u}$ is the maximum applied load at failure and $A$ is the cross-sectional area of the specimen.

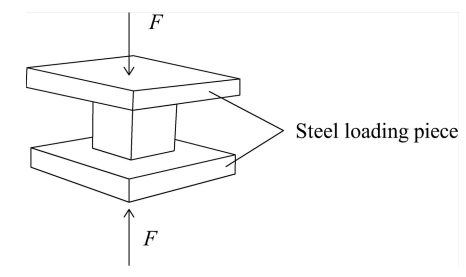

Figure 5. Illustration of cubic compressive strength test.

Figure 6 schematically describes the splitting tensile strength test used in the study. The loading rate is $0.05 \pm 0.01 \mathrm{MPa} / \mathrm{s}$. When the maximum applied load $F_{u}$ is reached, the $f_{t s}$ is given by

$$
f_{t s}=\frac{2 F_{u}}{\pi A}
$$

where the $A$ is equal to the square of side length of the cubic sample.

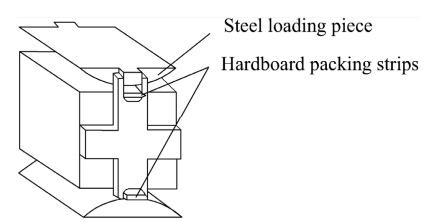

(a)

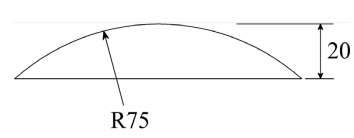

(b)

Figure 6. Illustration of splitting tensile strength test: (a) Loading configuration; (b) Sizes of steel loading piece.

It should be noted that the specimens in the splitting tensile strength test, as per BS EN 12390-6 [49], are cylinders with diameters $150 \mathrm{~mm}$ and heights $300 \mathrm{~mm}$. The test method is very similar to that recommended by Chinese standard GB/T 50081 [47]. However, the A in Equation (2) is equal to the product of the diameter and height of cylinder. 


\subsection{Test on Flexural Performance of ARGF-CAC}

The test of four-point-bending beams is carried out to evaluate both the flexural tensile strength and toughness of ARGF-CAC according to ASTM C1609/C1609M [50]. The width and depth of beam should be larger than three times of fiber length. Thus, the beams have sizes $100 \times 100 \times 400 \mathrm{~mm}^{3}$ and spans $300 \mathrm{~mm}$ for Type A ARGF-CAC. The width, depth, length, and span are $150 \mathrm{~mm}, 150 \mathrm{~mm}$, $550 \mathrm{~mm}$, and $450 \mathrm{~mm}$, respectively, for Type B ARGF-CAC beams. The bending test is performed on an electronic universal testing machine with the maximum range of $100 \mathrm{kN}$ as shown in Figure 7 . Herein, a thin steel plate hangs on the lateral side of beam with two ends fixed at the locations of hinge supports. Thus, it has the same displacement with the two hinge supports when the beam is subjected to the load. Moreover, a steel sheet is bonded on the lateral side of beam at the mid-span. A clip gauge with the maximum range of $4 \mathrm{~mm}$ is fixed between the steel sheet and thin plate. Thus, the net displacement of the beam at the mid-span without the effect of hinge support deformation can be directly measured from the clip gauge. The load is applied with the displacement rate $0.2 \mathrm{~mm} / \mathrm{min}$. of cross beam in the testing machine. All of the data record from the load and displacement cells can be simultaneously collected in a data acquisition system.

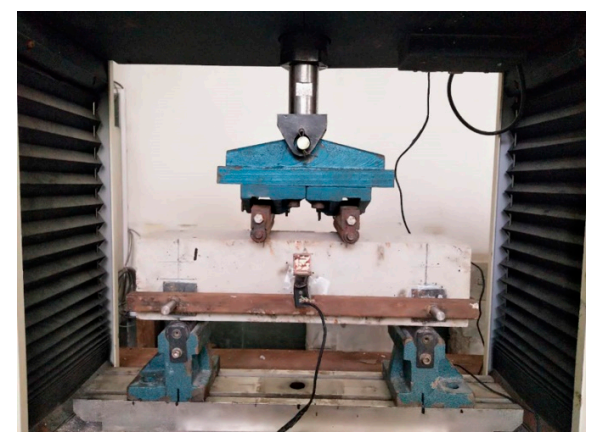

Figure 7. Test set-up for four-point-bending beam.

The flexural performance can be comprehensively analyzed by virtue of modulus of rupture $f_{\mathrm{r}}$, residual strengths $f_{600}^{D}$ and $f_{150}^{D}$ corresponding to net displacements $S / 600$ and $S / 150$ ( $S$ is the span length of beam), respectively, beam toughness $T_{150}^{D}$ (the area of the load-displacement curve from 0 to $S / 150$ ), and equivalent flexural strength ratio $R_{T, 150}^{D}$, which can be expressed in Equations (3) and (4), as follows [50].

$$
\begin{gathered}
R_{T, 150}^{D}=\frac{150 T_{150}^{D}}{f_{1} b h^{2}} \times 100 \% \\
f_{1}=\frac{F_{1} S}{b h^{2}}
\end{gathered}
$$

Herein, $b, h$, and $F_{1}$ are the beam width, beam height, and first peak load, respectively. $f_{1}$ is the first-peak strength corresponding to $F_{1}$ and equal to $f_{\mathrm{r}}$ if no first peak load can be detected in the load-displacement curve.

\subsection{Test on Bond Properties Between BFRP Bars and ARGF-CAC}

Pull-out tests of BFRP bars from ARGF-CAC with sizes of $150 \times 150 \times 150 \mathrm{~mm}^{3}$ are performed in order to study the bond properties between the two materials [51]. Optimized fiber content for the two types of ARGF is determined through evaluating the toughness of ARGF-CAC and adopted to study its influence on the bond behavior. Control specimens of CAC with no ARGF are prepared. There are three main groups of specimens in the pull-out test. In each main group, three bond lengths, i.e., $5 d$, $7.5 d$, and $10 d$ ( $d$ is the diameter of BFRP bar), are designed with five samples for each length. The bond length is controlled by using PVC tubes at two sides of steel mould, as shown in Figure 8. 


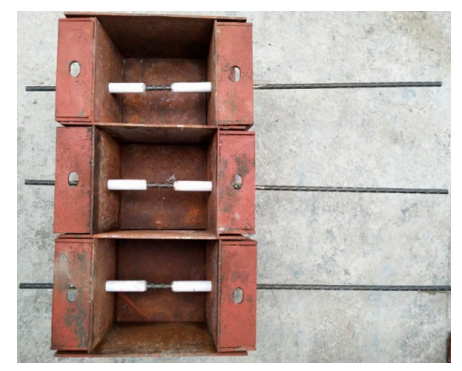

Figure 8. BFRP bars embedded in steel moulds.

The electronic universal testing machine with the maximum range of $100 \mathrm{kN}$ is adopted in order to perform pull-out test of BFRP bar from CAC, as shown in Figure 9. Herein, one end of BFRP bar passes through a hollow load cell, is embedded in a steel tube with epoxy and then clipped by the upper grip of testing machine. The load cell is set between the reaction steel plate and upper surface of concrete, and then can monitor the applied load during the pull-out process of BFRP bar. Besides, a displacement cell is tightly attached on the other end of BFRP bar with an extension rod touching on the lower surface of concrete. Thus, the slip between the concrete and BFRP bar at the free end can be measured. All of the data records from the load and displacement cells are simultaneously collected in a data acquisition system.

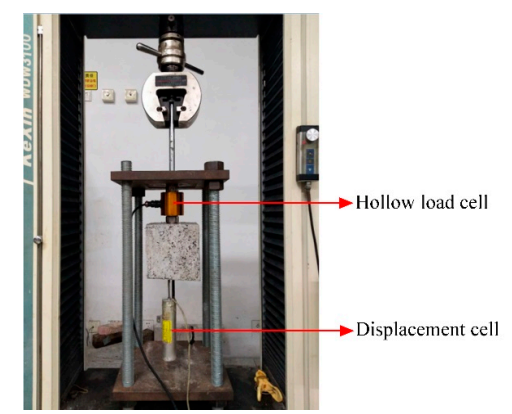

Figure 9. Test set-up for pull-out test.

\section{Analysis and Discussion on Test Results}

\subsection{Results of Slump Values of Fresh Concrete}

The slump values are $115 \pm 5 \mathrm{~mm}$ for each type of ARGF reinforced concrete. No segregation and bleeding are found in all the fresh mix.

\subsection{Pore Solution $p H$ Value}

The measured pore solution $\mathrm{pH}$ value range is $11.8-12$ and the addition of ARGFs has hardly the effect on the $\mathrm{pH}$ value.

\subsection{Results of Cubic Compressive Strength and Splitting Tensile Strength}

Figure 10 shows the average values of cubic compressive strength $f_{\text {cu }}$ varying with fiber contents indicating the maximum and minimum values for the two types of ARGF. When the fiber content is below $0.5 \%$ by volume, the $f_{\mathrm{cu}}$ almost keeps invariable for Type A ARGF, but shows a slight increase for Type B ARGF with the increasing of fiber content. However, when the fiber volume fraction exceeds $0.5 \%$, the average values of $f_{\text {cu }}$ are slightly reduced, as indicated by Sivakumaret al. [36]. As the fiber content further increases, the $f_{\mathrm{cu}}$ of Type A ARGF-CAC almost keeps constant, but the $f_{\mathrm{cu}}$ of Type B ARGF-CAC shows a small increment. In fact, the fibers distribute randomly in the concrete and may not be across the longitudinal cracks that are induced by the uni-axial compression. Moreover, 
even if some of the fibers just distribute across the cracks, the bridging action is so limited due to the insufficient anchorage length when the fibers are very short. If the fiber is long enough, such as Type B ARGF with the length of $36 \mathrm{~mm}$, the bridging effect becomes stronger as the fiber content increases. Thus, the $f_{\text {cu }}$ is slightly increased when the fiber volume fraction is larger than $1.0 \%$ for Type B ARGF-CAC. In summary, the maximum reduction (\%) of the average $f_{\mathrm{cu}}$ is $10.5 \%$ and $11.7 \%$ for Type A ARGF-CAC and Type B ARGF-CAC, respectively, as compared to plain CAC.

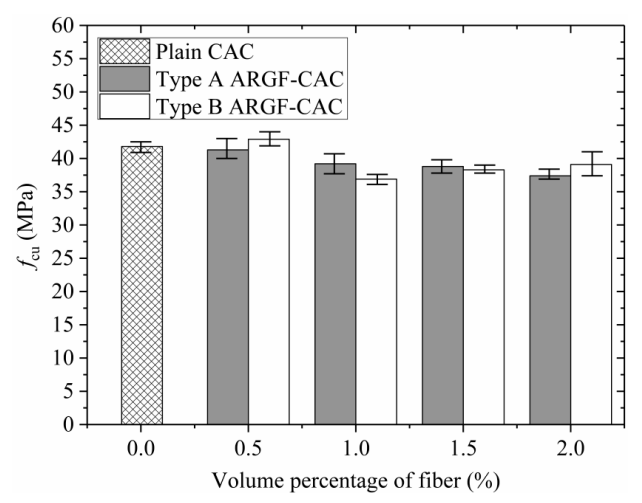

Figure 10. Variation $f_{\mathrm{cu}}$ with fiber content.

The average splitting tensile strength $f_{\mathrm{ts}}$ increases with the fiber content as shown in Figure 11, where the maximum and minimum values in each group are indicated. When the fiber volume fraction is below $1.0 \%$, the $f_{\text {ts }}$ shows marginal variation with the increasing of fiber content. As the fiber volume fraction further increases, the $f_{\text {ts }}$ is significantly increased and the maximum increment (\%) is $18.4 \%$ and $27 \%$ for Type A ARGF-CAC and Type B ARGF-CAC, respectively, compared to plain CAC. It demonstrates that both the two types of ARGFs can provide good resistance to crack propagation in the concrete under splitting tension. Moreover, when the fiber volume fractions are the same, the $f_{\text {ts }}$ is generally improved as the fiber length is longer.

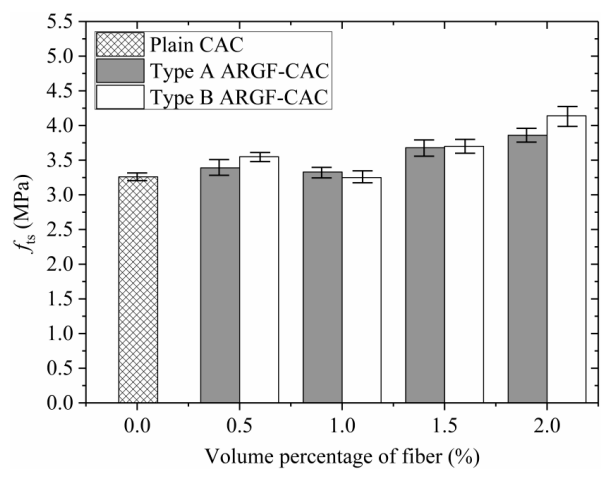

Figure 11. Variation of $f_{\text {ts }}$ with fiber content.

\subsection{Results of Flexural Performance}

Figure 12 shows typical curves of applied load $F$ varying with the net displacement $\Delta$ at the mid-span of beam for both the two types of ARGF. It can be seen that the $F$ increases almost linearly up to a critical load with the increasing of $\Delta$ where the cracks initiate from the bottom of beam. A small non-linear portion is observed in each curve until the maximum load is reached. No first peak load is found in all of the specimens. Subsequently, the $F$ gradually decreases with the increasing of $\Delta$ until the beam fails. Moreover, more than $80 \%$ of fibers are found to be fractured finally in the critical cross-section, irrespective of fiber type. It means the two types of ARGF used in the study have good bond performance with the CAC. 


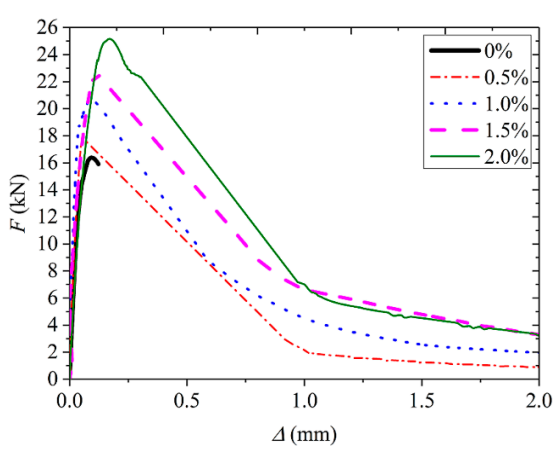

(a)

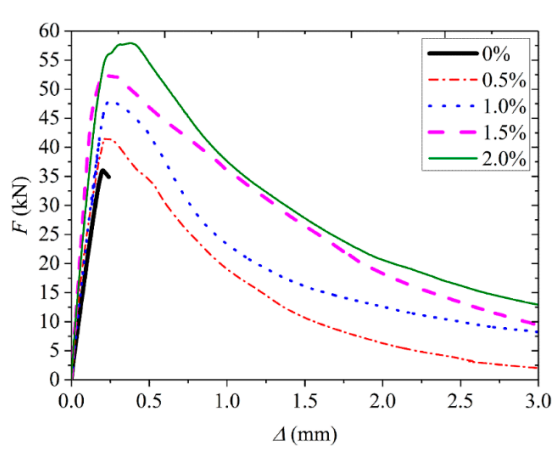

(b)

Figure 12. F- $\triangle$ curve: (a) Type A ARGF-CAC; and, (b) Type B ARGF-CAC.

As the fiber content increases, the peak load is improved due to the stronger bridging effect. Stable descending process can be detected in ARGF-CAC beams. When the fiber volume fraction attains $1.5 \%$, the absolute value of descending slope seems to be the lowest. It demonstrates that the addition of the two types of ARGF can significantly improve the strength and toughness of CAC. However, when the fiber content is larger than $1.5 \%$ by volume, the mixing becomes too difficult to be sufficient, as indicated in Section 2.3. Therefore, the descending part of curve is steeper in the CAC beams with ARGF volume fraction $2 \%$ than that with ARGF volume fraction $1.5 \%$, as shown in Figure 12.

Moreover, the variations of $f_{\mathrm{r}}, f_{600}^{D}, f_{150}^{D}, T_{150}^{D}$, and $R_{T, 150}^{D}$ with fiber contents indicating the maximum and minimum values are shown in Figures 13-17. When the fiber volume fraction is increased from $0.5 \%$ to $1.0 \%$, the $f_{\mathrm{r}}, T_{150}^{D}$ and $R_{T, 150}^{D}$ have significant increments for each type of ARGF. It again demonstrates that the addition of ARGF can improve both the tensile strength and toughness of CAC. However, if the fiber content increases further, the increases of the mentioned parameters become smaller. When the volume percentage attains $2.0 \%$, the fibers' distribution in the concrete cannot be as uniform as that in the concrete with fewer fibers, mainly because much difficulty will be encountered in concrete mixing as the fiber content increases. Therefore, the improvement of tensile strength and toughness is very limited if the volume fraction is increased from $1.5 \%$ to $2.0 \%$. For Type A ARGF-CAC, it can be seen that the $f_{600}^{D} / f_{r}$ are $57.2 \%, 52.2 \%, 66.3 \%$, and $71.1 \%$ for fiber volume fractions $0.5 \%, 1.0 \%, 1.5 \%$, and $2.0 \%$, respectively. The $f_{150}^{D} / f_{r}$ are $4.5 \%, 9.6 \%, 14.6 \%$, and $13 \%$ for the four fiber contents, respectively. For Type B ARGF-CAC, the values of $f_{600}^{D} / f_{r}$ and $f_{150}^{D} / f_{r}$ corresponding to the four fiber volume fractions are $82.2 \%, 87.9 \%, 89.4 \%, 93.9 \%$ and $5.2 \%, 17.1 \%, 17.6 \%, 22.4 \%$, respectively. The addition of ARGF into CAC results in high residual strength retention, which increases with the increasing of fiber content and length.

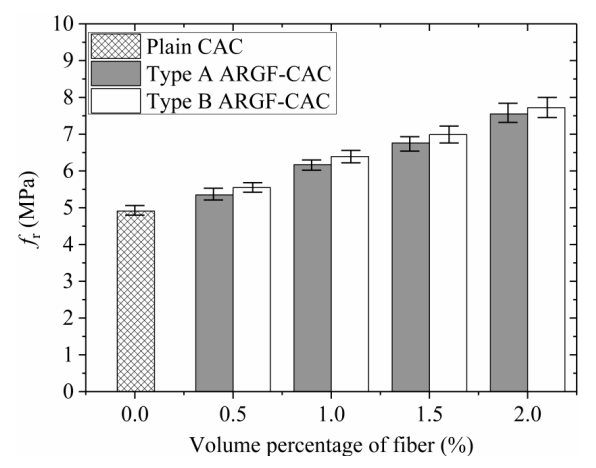

Figure 13. Variation of $f_{\mathrm{r}}$ with fiber content. 


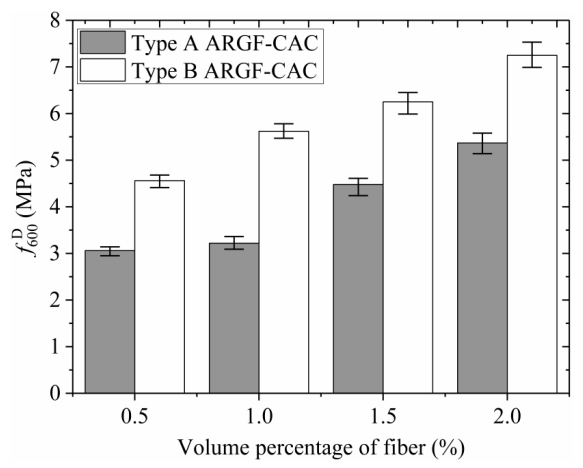

Figure 14. Variation of $f_{600}^{D}$ with fiber content.

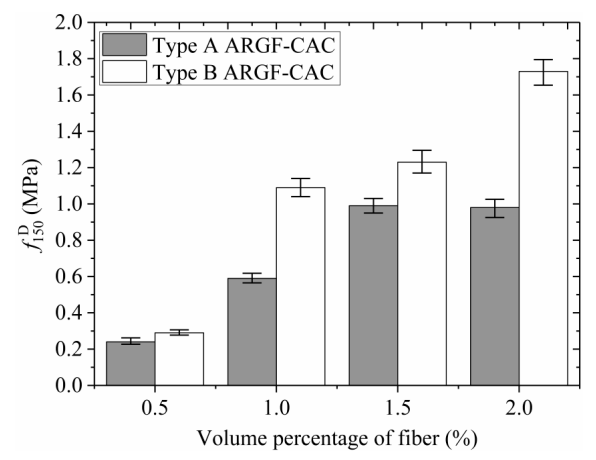

Figure 15. Variation of $f_{150}^{D}$ with fiber content.

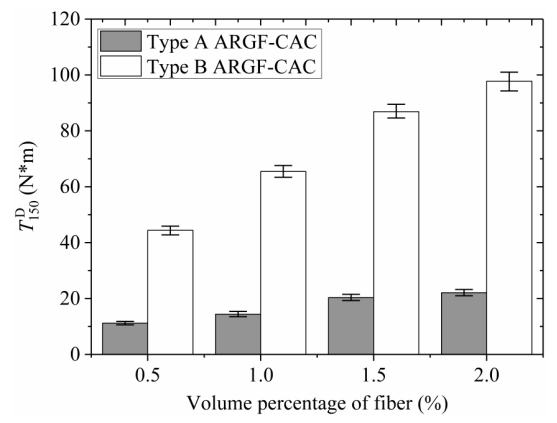

Figure 16. Variation of $T_{150}^{D}$ with fiber content.

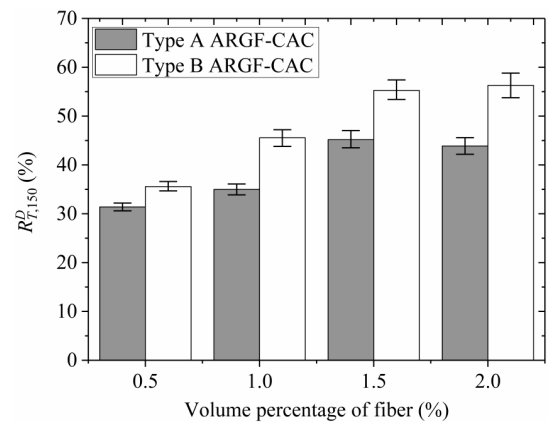

Figure 17. Variation of $R_{T, 150}^{D}$ with fiber content.

According to the above analysis in the present study, the optimized fiber volume fraction for the two types of ARGFs should be $1.5 \%$ by considering actual mixing process of fibers in fresh concrete. Thus, the following section will be aimed at the bond performance between BFRP bars and ARGF-CAC with fiber volume fractions 1.5\%. Moreover, the specimens of BFRP bars that are bonded to plain CAC are used for the control ones. 


\subsection{Bond Properties Between BFRP Bars and ARGF-CAC}

As discussed above, the present study is only aimed at the bond properties between BFRP bars and ARGF-CAC with volume fractions 1.5\%. Control specimens are prepared for the bond behavior of BFRP bars with plain CAC. The intention of this section is to compare the pull-out behaviors of BFRP bars from CAC with different fiber types and different bond lengths. However, it should be noted that the actual bond length $L$ may be varied, even for the same nominal bond length $(5 d, 7.5 d$, or $10 d$ ). Thus, the average bond stress $\tau_{\text {avg }}$ determined by Equation (5) is introduced for the sake of comparison. Figure 18 summarizes the typical $\tau_{\text {avg }}-\delta$ curves under different conditions. Moreover, the specimens have the failure modes of BFRP bar pull-out from the concrete in general. Only three specimens of plain CAC bonded with BFRP bars having nominal bond lengths $10 d$ fail by concrete fracturing before the bars are pulled out.

$$
\tau_{a v g}=\frac{F}{\pi d L}
$$

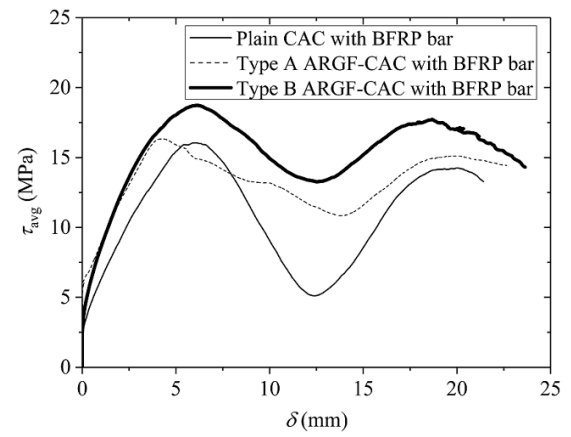

(a)

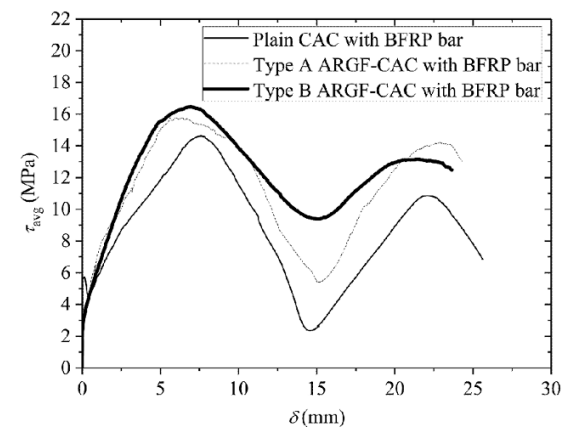

(b)

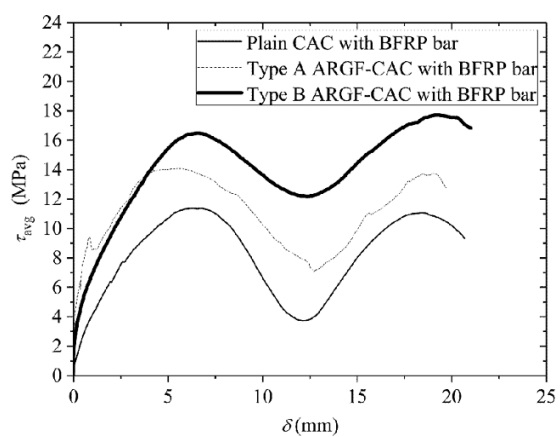

(c)

Figure 18. $\tau_{\mathrm{avg}}-\delta$ curves for BFRP bar: (a) $L=5 d$; (b) $L=7.5 d$; and, (c) $L=10 d$.

Very similar to the pull-out behavior of FRP bar from CAC [13] and alkali-activated slag seawater sea sand concrete [52], the $\tau_{\mathrm{avg}}-\delta$ curve of each specimen still includes four stages. At the beginning of loading, the $F$ or $\tau_{\text {avg }}$ increases with no slip until the frictional stress $\tau_{\mathrm{s}}$ is exceeded. Subsequently, the $\tau_{\text {avg }}$ is further increased with the increasing of $\delta$, but the ascending slope becomes lower. When the maximum value is reached, the applied load is gradually reduced, but the $\delta$ still increases. The final part of each curve is a fluctuation line that is also verified in the bond behavior between FRP bar and alkali-activated slag seawater sea sand concrete [52]. In fact, the bond action almost disappears in the stage and the resistance is mainly provided by interfacial residual friction. The residual frictional stress $\tau_{\mathrm{s}}$ is then adopted as the average value between the maximum and minimum values at the frictional stage. 
The variations of maximum average bond stress $\tau_{\mathrm{avg} \text {-max }}$ and residual frictional stress $\tau_{\mathrm{s}}$ with the nominal bond length being shown in Figure 19. The maximum and minimum values of the $\tau_{\text {avg-max }}$ and $\tau_{\mathrm{s}}$ in each group are also included in Figure 19. As the nominal bond length increases, the average values of $\tau_{\text {avg-max }}$ and $\tau_{\mathrm{s}}$ commonly decrease. The reasons can be explained, as follows. First, it is acceptable that the non-uniformity of interfacial stress distribution becomes more significant as the bond length increases. It then results in the reductions of the two parameters with the increasing of $L$. Second, the BFRP bars used in the test have shallow ribs on the surfaces. As the bar is pulled out from the concrete, the ribs are seriously detached from the BFRP surface, as shown in Figure 20. The detached ribs may give local compression with surrounding concrete. The local action is stronger as the bond length is shorter, as indicated by Yang et al. [52]. Thus, the average values of $\tau_{\text {avg-max }}$ and $\tau_{\mathrm{s}}$ for specimens with $L=5 d$ are larger. Besides, radial compression on the bar-to-concrete interface provided by the ribs is inevitable. It may be so strong that the concrete would be cracked along the radial direction. The longer the bond length is, the larger the crack opens. The concrete would be completely fractured before the bar is pulled out if the $L$ is long enough, such as some of the specimens with nominal bond lengths $10 \mathrm{~d}$. The $\tau_{\mathrm{avg} \text {-max }}$ and $\tau_{\mathrm{s}}$ are reduced as the radial cracks develop in the concrete. Moreover, the values of $\tau_{\mathrm{s}}$ from different specimens are relatively scattered, because the detachment levels of BFRP surfaces are different along the embedment length.

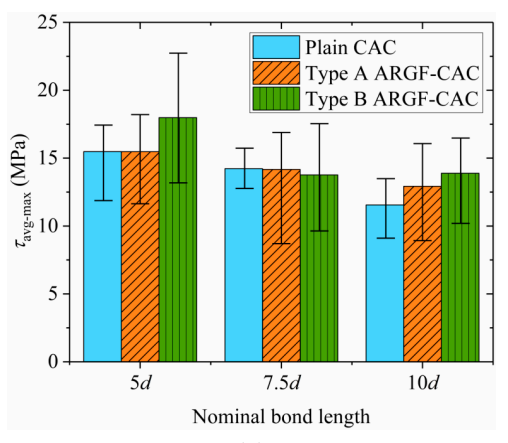

(a)

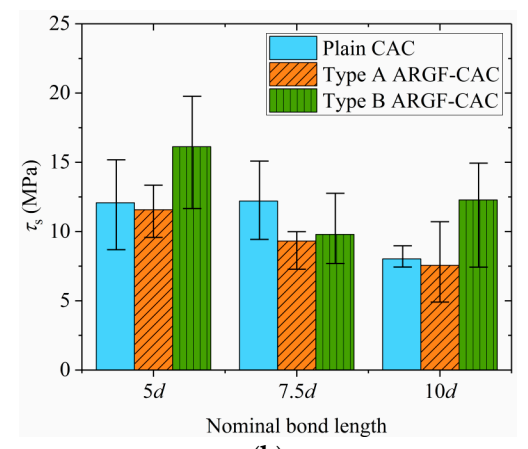

(b)

Figure 19. Effects of nominal bond length: (a) $\tau_{\mathrm{avg} \text {-max }}$ (b) $\tau_{\mathrm{s}}$.

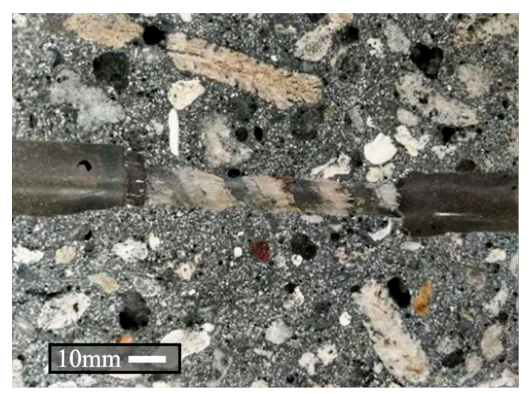

Figure 20. Detached ribs on the surface of fiber-reinforced polymer (FRP) bar.

When the ARGFs are added into the CAC, the $\tau_{\text {avg-max }}$ shows a certain increment. It means that the ARGFs can provide good bridging action on the crack development in the concrete. However, for Type A ARGF, the increase is marginal. If the Type B ARGF is used, the $\tau_{\text {avg-max }}$ is significantly improved. When the $L$ is increased from $7.5 d$ to $10 d$, the reduction of $\tau_{\text {avg-max }}$ is apparently lower for ARGF-CAC. It demonstrates again that the development of cracks in the concrete is well restricted with the addition of ARGFs. Moreover, the Type A ARGF has a marginal effect on the $\tau_{\mathrm{s}}$, but the incorporation of Type B ARGFs apparently increases the $\tau_{\mathrm{s}}$. 


\section{Conclusions}

The present study is mainly aimed at the mechanical properties of ARGF reinforced CAC. Two types of ARGF, denoted by Type A and Type B, are used here. Tests of basic mechanical properties and flexural performance are carried out on both the plain CAC and ARGF-CAC with four contents by volume, i.e., $0.5 \%, 1.0 \%, 1.5 \%$, and $2.0 \%$, for the two types of ARGF. The optimized fiber volume fractions for both types of ARGF are determined based on evaluating both the workability and mechanical properties of ARGF-CAC. Moreover, a central pull-out test is performed in order to study the bond performance between BFRP bars and both the plain CAC and ARGF-CAC with the optimized fiber volume fraction. Three nominal bond lengths $(5 d, 7.5 d$, and $10 d)$ are considered for each type of concrete. The main conclusions are then drawn, as follows.

(1) As the fiber content increases, the workability of fresh concrete becomes weaker. The average value of $f_{\mathrm{cu}}$ increases as the fiber volume fraction is increased to $0.5 \%$, especially for Type B ARGF. When the fiber volume fraction exceeds $0.5 \%$, however, the average values of $f_{\mathrm{cu}}$ are slightly reduced for either Type A or Type B ARGF. As the fiber content further increases, the $f_{\text {cu }}$ of Type A ARGF-CAC almost keeps constant, but the $f_{\text {cu }}$ of Type B ARGF-CAC shows a small increment. But the $f_{\mathrm{ts}}$ and $f_{\mathrm{r}}$ are generally improved with the increasing of fiber volume fraction.

(2) Both the residual strength retention and flexural toughness are improved, as more ARGFs are added into CAC, and higher with Type B ARGF addition when compared to Type A ARGF. The improvement becomes smaller when the volume fraction of ARGF exceeds $1.0 \%$ for either Type A or Type B ARGF. The optimized volume fraction is $1.5 \%$ for both the two types of ARGF by considering the workability and mechanical performance of ARGF-CAC.

(3) More than $90 \%$ of the specimens have the failure modes of BFRP bar pull-out from the concrete. Only three specimens of plain CAC bonded with BFRP bars having nominal bond lengths 10d are damaged by concrete fracturing before the bars are pulled out. When the bar is pulled out, the ribs on the surface are seriously detached.

(4) Both the $\tau_{\text {avg-max }}$ and $\tau_{\mathrm{s}}$ are reduced if $L>5 d$. The values of $\tau_{\mathrm{s}}$ show relatively large scatters due to the random detachment of ribs on the BFRP surface. When the Type B ARGFs are added into the CAC, the $\tau_{\text {avg-max }}$ is increased significantly. However, the Type A ARGFs seem to have marginal effect on the bond performance.

Author Contributions: Conceptualization, S.Y. and K.D.; Data curation, M.Y. and Y.Y.; Funding acquisition, S.Y.; Methodology, S.Y.; Writing—original draft, S.Y.; Writing—review \& editing, S.Y. and K.D. All authors have read and agreed to the published version of the manuscript.

Funding: This research was funded by National Natural Science Foundation of China (Grant 51778591), and Qingdao Zhuhua Environmental Protection \& Technology Co., Ltd. (Grant number 911991230).

Acknowledgments: The authors would like to thank the anonymous reviewers for their constructive suggestions to improve the quality of the paper.

Conflicts of Interest: The authors declare no conflict of interest.

\section{References}

1. Ali, M.B.; Saidur, R.; Hossain, M.S. A review on emission analysis in cement industries. Renew. Sustain. Energy Rev. 2011, 15, 2252-2261. [CrossRef]

2. Davidovits, J. Geopolymers: Inorganic polymeric new materials. J. Therm. Anal. Calorim. 1991, 37, 1633-1656. [CrossRef]

3. Shi, C.J.; Roy, D.; Krivenko, P. Alkali-Activated Cements and Concretes; Taylor and Francis: Abingdon, UK, 2006.

4. Abdollahnejad, Z.; Mastali, M.; Falah, M.; Luukkonen, T.; Mazari, M.; Illikainen, M. Construction and demolition waste as recycled aggregates in alkali-activated concretes. Materials 2019, 12, 4016. [CrossRef] [PubMed]

5. Małek, M.; Łasica, W.; Jackowski, M.; Kadela, M. Effect of waste glass addition as a replacement for fine aggregate on properties of mortar. Materials 2020, 13, 3189. [CrossRef] 
6. Shi, C.J.; Li, Y.K.; Zhang, J.K.; Li, W.G.; Chong, L.L.; Xie, Z.B. Performance enhancement of recycled concrete aggregate-A review. J. Clean. Prod. 2016, 112, 466-472. [CrossRef]

7. Whole Building Design Guide (WBDG). UFC 3-440-05N: Estimating Energy and Water Consumption for Shore Facilities and Cold Iron Support for Ships, Cancelled without Replacement; WBDG: Washington, DC, USA, 16 January 2014.

8. Chen, Z.; Sun, G.; Tang, X.; Liu, Y. Study on applications of concrete from coral reef sand mixed with seawater for patching-up in reef engineering. Coast. Eng. 2008, 27, 60-69. (In Chinese)

9. Arumugam, R.A.; Ramamurthy, K. Study of compressive strength characteristic of coral aggregate concrete. Mag. Concr. Res. 1996, 48, 141-148. [CrossRef]

10. Wei, Z.; Li, Z.; Shen, J. Research on the influencing factors of performance of coral concrete and its early mechanical property. Ind. Constr. 2017, 47, 130-136. (In Chinese)

11. Wang, L.; Fan, L. Analysis of strength properties and failure modes of coral aggregate concrete. China Concr. Cem. 2015, 1, 1-4. (In Chinese)

12. Zhao, Y.; Han, C.; Zhang, S.; Ge, R. Experimental study on the compression age strength of seawater coral concrete. Concrete 2011, 256, 43-45. (In Chinese)

13. Yang, S.; Yang, C.; Huang, M.; Liu, Y.; Jiang, J.; Fan, G. Study on bond performance between FRP bars and seawater coral aggregate concrete. Constr. Build. Mater. 2018, 173, 272-288. [CrossRef]

14. Chen, Z.; Chen, T.; Qu, J. A feasibility study of application of coral reef sand concrete. Ocean Eng. 1991, 9, 67-80. (In Chinese)

15. Wang, Q.; Li, P.; Tian, Y.; Chen, W.; Su, C. Mechanical properties and microstructure of Portland cement concrete prepared with coral reef sand. J. Wuhan Univ. Technol. Mater. Sci. Ed. 2016, 31, 996-1001. [CrossRef]

16. Xu, W.; Yang, S.; Xu, C.; Sun, H. Study on fracture properties of alkali-activated slag seawater coral aggregate concrete. Constr. Build. Mater. 2019, 223, 91-105. [CrossRef]

17. Ding, L.; Shi, J.; Wang, X.; Liu, Y.; Jin, Y.; Wu, Z. Bond behavior between basalt fiber-reinforced polymer rebar sand coral-reef-sand concrete conditioned in saline solution. Struct. Concr. 2020, 21, 659-672. [CrossRef]

18. Lyu, B.; Wang, A.; Zhang, Z.; Liu, K.; Xu, H.; Shi, L.; Sun, D. Coral aggregate concrete: Numerical description of physical, chemical and morphological properties of coral aggregate. Cem. Concr. Compos. 2019, 100, $25-34$. [CrossRef]

19. Cheng, S.; Shui, Z.; Sun, T.; Yu, R.; Zhang, G.; Ding, S. Effects of fly ash, blast furnace slag and metakaolin on mechanical properties and durability of coral sand concrete. Appl. Clay. Sci. 2017, 141, 111-117. [CrossRef]

20. Yang, S.; Zhang, X.; Yu, M.; Yao, J. An analytical approach to predict fracture parameters of coral aggregate concrete immersed in seawater. Ocean. Eng. 2019, 191, 106508. [CrossRef]

21. Wang, L.; Mao, Y.; Lv, H.; Chen, S.; Li, W. Bond properties between FRP bars and coral concrete under seawater conditions at 30,60 , and $80^{\circ} \mathrm{C}$. Constr. Build. Mater. 2018, 162, 442-449. [CrossRef]

22. Wang, J.; Feng, P.; Hao, T.Y.; Yue, Q.R. Axial compressive behavior of seawater coral aggregate concrete filled FRP tubes. Constr. Build. Mater. 2017, 147, 272-285. [CrossRef]

23. Wang, A.; Lyu, B.; Zhang, Z.; Liu, K.; Xu, H.; Sun, D. The development of coral concretes and their upgrading technologies: A critical review. Constr. Build. Mater. 2018, 187, 1004-1019. [CrossRef]

24. Da, B.; Yu, H.; Ma, H.; Tan, Y.; Mi, R.; Dou, X. Experimental investigation of whole stress-strain curves of coral concrete. Constr. Build. Mater. 2016, 122, 81-89. [CrossRef]

25. Da, B.; Yu, H.; Ma, H.; Tan, Y.; Wu, Z. Research on compression behavior of coral aggregate reinforced concrete columns under large eccentric compression loading. Ocean Eng. 2018, 155, 251-260. [CrossRef]

26. Wang, L.; Yi, J.; Deng, X.; Li, J. Study on mechanical property and damage morphology analysis of coral aggregate concrete with fiber. J. Henan Polytech. Univ. 2016, 35, 713-718. (In Chinese)

27. Wang, Y.; Zhang, S.; Niu, D.; Su, L.; Luo, D. Strength and chloride ion distribution brought by aggregate of basalt fiber reinforced coral aggregate concrete. Constr. Build. Mater. 2020, 234, 117390. [CrossRef]

28. Niu, D.; Su, L.; Luo, Y.; Huang, D.; Luo, D. Experimental study on mechanical properties and durability of basalt fiber reinforced coral aggregate concrete. Constr. Build. Mater. 2020, 237, 117628. [CrossRef]

29. Małek, M.; Jackowski, M.; Łasica, W.; Kadela, M. Characteristics of recycled polypropylene fibers as an addition to concrete fabrication based on Portland cement. Materials 2020, 13, 1827. [CrossRef]

30. Kim, J.; Park, C.; Lee, S.; Lee, S.; Won, J. Effects of the geometry of recycled PET fiber reinforcement on shrinkage cracking of cement-based composites. Compos. Part B Eng. 2008, 39, 442-450. [CrossRef] 
31. Gao, S.L.; Mäder, E.; Abdkader, A.; Offermann, P. Environmental resistance and mechanical performance of alkali-resistant glass fibers with surface sizings. J. Non Cryst. Solids 2003, 325, 230-241. [CrossRef]

32. Mirza, F.A.; Soroushian, P. Effects of alkali-resistant glass fiber reinforcement on crack and temperature resistance of lightweight concrete. Cem. Concr. Compos. 2002, 24, 223-227. [CrossRef]

33. Qin, X.; Li, X.; Cai, X. The applicability of alkaline-resistant glass fiber in cement mortar of road pavement: Corrosion mechanism and performance analysis. Int. J. Pave. Res. Tech. 2017, 10, 536-544.

34. Domagaa, L.; Bizoń-Żabińska, E.; Kurzyniec, K. The influence of alkali-resistant glass fibres on properties of fine-aggregate concretes. MATEC Web Conf. 2019, 262, 06003. [CrossRef]

35. Zhu, Z.; Zhang, C.; Meng, S.; Shi, Z.; Tao, S.; Zhu, D. A statistical damage constitutive model based on the Weibull distribution for alkali-resistant glass fiber reinforced concrete. Materials 2019, 12, 1908. [CrossRef] [PubMed]

36. Sivakumar, V.R.; Kavitha, O.R.; Prince Arulraj, G.; Srisanthi, V.G. An experimental study on combined effects of glass fiber and Metakaolin on the rheological, mechanical, and durability properties of self-compacting concrete. Appl. Clay Sci. 2017, 147, 123-127. [CrossRef]

37. Sivakumar, A.; Santhanam, M. Mechanical properties of high strength concrete reinforced with metallic and non-metallic fibres. Cem. Concr. Compos. 2007, 29, 603-608. [CrossRef]

38. Barluenga, G.; Hernández-Olivares, F. Cracking control of concretes modified with short AR-glass fibers at early age. Experimental results on standard concrete and SCC. Cem. Concr. Res. 2007, 37, 1624-1638. [CrossRef]

39. Gao, S.L.; Mäder, E.; Abdkader, A.; Offermann, P. Sizings on alkali-resistant glass fibers: Environmental effects on mechanical properties. Langmuir 2003, 19, 2496-2506. [CrossRef]

40. Arabi, N.; Molez, L.; Rangeard, D. Durability of alkali-resistant glass fibers reinforced cement composite: Microstructural observations of degradation. Period. Polytech. Civ. Eng. 2018, 62, 1-7. [CrossRef]

41. Nourredine, A. Influence of curing conditions on durability of alkali-resistant glass fibers in cement matrix. Bull. Mater. Sci. 2011, 34, 775-783. [CrossRef]

42. Kwan, W.H.; Cheah, C.B.; Ramli, M.; Chang, K.Y. Alkali-resistant glass fiber reinforced high strength concrete in simulated aggressive environment. Mater. Constr. 2018, 68, 1-14. [CrossRef]

43. Lu, J.; Chen, H.; Lin, Y.; Li, Z.; Hong, W.; Wu, J. Effect of fiberglass on mechanical properties and durability of coral concrete. Guangzhou Chem. Indust. 2016, 44, 52-54.

44. British Standards Institution (BSI). BS EN 1926-2: Method of Testing Cement Part 2: Chemical Analysis of Cement; BSI Standards Publication: London, UK, 2013.

45. British Standards Institution (BSI). BS EN 12350-2: Testing Fresh Concrete Part 2: Slump Test; BSI Standards Publication: London, UK, 2009.

46. Rilem Technical Committees. RILEM TC 178-TMC: Testing and modelling chloride penetration in concrete. Analysis of water-soluble chloride content in concrete recommendation. Mater. Struct. 2002, 35, 586-588.

47. Ministry of Housing and Urban-Rural Construction of the People's Republic of China. Standard for Test Method of Mechanical Properties on Ordinary Concrete; China Building Industry Press: Beijing, China, 2002.

48. British Standards Institution (BSI). BS EN 12390-3: Testing Hardened Concrete Part 3: Compressive Strength of Test Specimens; BSI Standards Publication: London, UK, 2009.

49. British Standards Institution (BSI). BS EN 12390-6: Testing Hardened Concrete Part 6: Tensile Splitting Strength of Test Specimens; BSI Standards Publication: London, UK, 2009.

50. ASTM International. ASTM C1609/C1609M: Standard Test Method for Flexural Performance of Fiber-Reinforced Concrete (Using Beam with Third-Point Loading); ASTM International: West Conshohocken, PA, USA, 2012.

51. ACI Committee 440. ACI 440.3R-04: Guide Test Methods for Fiber-Reinforced Polymers (FRPs) for Reinforcing or Strengthening Concrete Structures; ACI Committee 440, American Concrete Institute: Farmington Hills, MI, USA, 2004.

52. Yang, S.; Xu, J.; Zang, C.; Li, R.; Yang, Q.; Sun, S. Mechanical properties of alkali-activated slag concrete mixed by seawater and sea sand. Constr. Build. Mater. 2019, 196, 395-410. [CrossRef]

(C) 2020 by the authors. Licensee MDPI, Basel, Switzerland. This article is an open access article distributed under the terms and conditions of the Creative Commons Attribution (CC BY) license (http://creativecommons.org/licenses/by/4.0/). 